\title{
PERANCANGAN COWPER GUNA PEMANFAATAN GAS BUANG PELEBURAN LOGAM
}

\author{
Yoska Octaviano, Yusep Mujalis, Benny Siantury, Tono Sukarnoto dan \\ Rianti Dewi Sulamet-Ariobimo \\ Jurusan Teknik Mesin, Fakultas Teknologi Industri Universitas Trisakti \\ e-mail: rianti.ariobimo@gmail.com
}

\begin{abstract}
A prototype of homemade furnace was built and the highest temperature it can reach during the trial process is approximately $400^{\circ} \mathrm{C}$. Beside liquid metal, the furnace also produced exhaust gas as a side product. The exhaust gas is still hot. Hot gas can be used to improve the furnace's temperature based on blast furnace method. To apply this method, the furnace should be companied with cowper. In designing cowper, several parameters should be notice. The parameters are hot gas temperature, air flow direction, and its movement ability with the furnace. Hot gas temperature will determine the number of heat absorber layers. The direction of the air flow will determine the cowper construction. Movement ability is associated with space. The design is made based on VDI 2221. The cowper design concept is cowper to store hot gas made of ramming refectories with its outer diameter similar to oil tank and the movement mechanism only applied for migration.
\end{abstract}

Keywords: Cowper, furnace, exhaust gas, air flow direction, refectories.

\section{PENDAHULUAN}

Dalam peleburan logam akan diperoleh gas sebagai hasil sampingan. Gas ini mempunyai temperatur yang tinggi tetapi kandungan oksigennya rendah. Walaupun demikian dengan menggunakan teknologi tertentu, gas ini tetap dapat dimanfaat. Salah satu diantaranya adalah penggunaan Cowper. Cowper adalah sebuah wadah yang berisi kisi-kisi batu tahan api. Prinsip dasar Cowper adalah perpindahan panas regeneratif [3]. Gas panas yang masuk ke dalam Cowper akan diserap panasnya ketika melewati kisi-kisi batu tahan api dan keluar sebagai gas dengan temperatur ruang. Panas itu akan tetap tersimpan dalam cowper sampai ada udara dingin yang kaya oksigen masuk ke dalam Cowper dan mengambil panasnya ketika melewati kisi-kisi batu tahan api tersebut.Udara ini akan mempunyai temperatur yang tinggi dan kaya oksigen sehingga dapat langsung dimanfaatkan. Cowper dikenal juga dengan nama hot blast stove dan Cowper stove. Teknologi Cowper dikembangkan untuk mendukung penyediaan udara panas yang konstan secara aliran dan temperatur untuk tanur tinggi (blast furnace) [3].

Udara panas dengan temperatur yang tinggi tersebut dapat dimanfaatkan untuk banyak hal, tetapi yang paling sering adalah untuk meningkatkan temperatur dapur peleburan. Dengan dimanfaatkannya udara panas kaya oksigen ini maka proses peleburan menjadi semakin cepat sehingga bahan bakar yang digunakan dapat dihemat.

Ziebiks dan Stanek melakukan penelitian terkait dengan aplikasi model matematik pada tanur tinggi dan karakteristik energi dari Cowper. Penelitian ini mereka lakukan untuk mengindentifikasikan parameter kerja tanur tinggi dan nilai energi bersih dari tanur tinggi. Selain itu mereka juga membahas pengaruh injeksi bahan bakar dan peningkatan temperatur tanus tinggi terhadap fluks energi kimia, komposisi kimianya dan nilai kalor dari gas yang dipergunakan oleh pihak lain. Kesimpulan yang diperoleh adalah model matematik ini dapat diaplikasikan pada manajemen energi dari peleburan bijih besi [8]. Sedangkan sebelumnya, Ridgion membangun sebuah simulasi komputer analog untuk membantu perhitungan persamaan diferensial pada desain Cowper. Hasil perhitungan simulasi dibandingkan dengan solusi digital sederhana. Kesimpulan yang diperoleh adalah perhitungan simulasi komputer analog dapat digunakan secara terbatas pada kasus-kasus tertentu [3]. Tscheliesnig dan Schauritsch menerapkan metode pengujian acoustic emission (AE) pada uji coba sebuah Cowper baru [5]. Kesimpulan yang diperoleh adalah penggunaan metode pengujian dan monitoring acoustic emission pada cowper dapat diandalkan dan ekonomis dalam memprediksi kegagalan yang mungkin terjadi. Dai melakukan penelitian terkait pemanas keramik yang digunakan dalam Cowper [2]. Dai memperoleh kesimpulan bahwa 
penggunaan pemanas keramik akan memberikan effisiensi pembakaran yang tinggi dan memenuhi persyaratan proses serta dapat mengurangi penggunaan energi.

Paper ini membahas perancangan pembuatan cowper sebagai pelengkap tungku peleburan logam yang sudah dibuat sebelumnya. Cowper yang dirancang harus sederhana, mudah dalam pengoperasiannya, dan murah seperti halnya tungku peleburan yang sudah berhasil dibuat oleh Yusep dkk [6], agar masyarakat dapat menggunakannya bersama-sama tungku peleburan untuk mendaur ulang logam dengan proses peleburan yang membutuhkan temperatur lebih tinggi. Perancangan cowper ini dibuat mengikuti VDI 2221 (Pahl dan Beitz, 1984). Berdasarkan metoda VDI 2221 tersebut maka perancangan ini akan melewati dua tahapan, yaitu: klarifikasi tugas dan perancangan. Perancangan sendiri akan terdiri atas tiga tahapan, yaitu perancangan konsep, perancangan wujud, dan perancangan detail. Klarifikasi tugas akan memberikan spesifikasi peralatan. Perancangan konsep akan menghasilkan abstraksi perancangan, struktur fungsi, prinsip solusi, konsep varian, dan evaluasi varian untuk rancangan yang sesuai dan optimum. Perancangan wujudakan memberikan prinsip yang akan digunakan, sedangkan perancangan detail akan memberikan gambar desain terpilih [4].

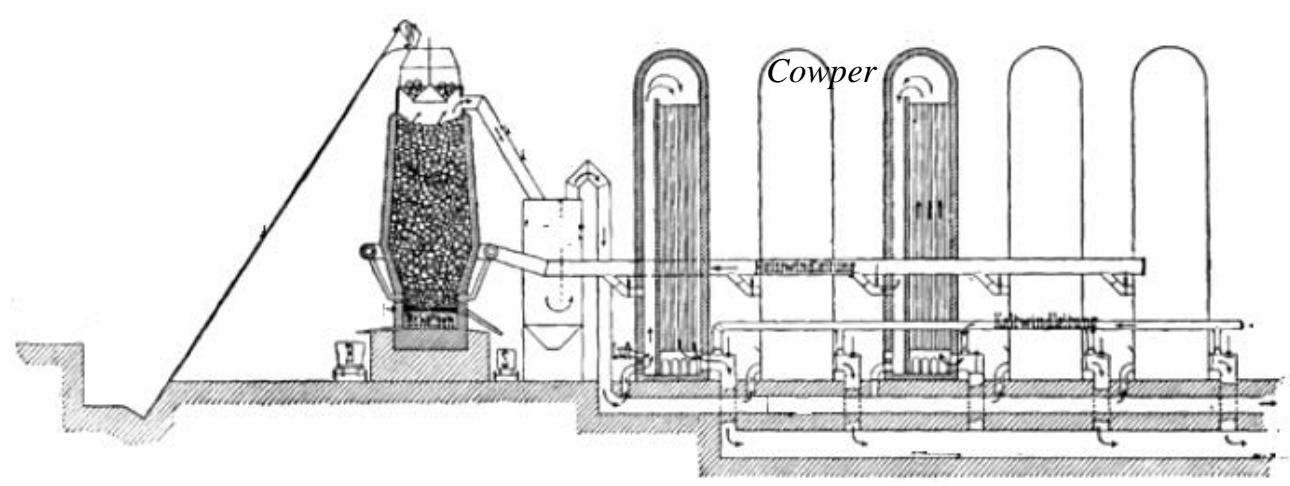

Gambar 1. Dapur peleburan menggunakan sistem cowper [7]

\section{METODA PENELITIAN}

Dapur peleburan yang menggunakan sistem cowper dapat dilihat pada Gambar 1. Proses perancangan Cowper dimulai dengan melakukan pengamatan dan evaluasi pada prototipe dapur peleburan (Mujalis dkk, 2014); kemudian dilanjutkan dengan pengamatan dan pengumpulan informasi terkait dengan spesifikasi (demands) yang harus dipenuhi dan keinginan pengguna (wishes) untuk membuat klarifikasi tugas. Selanjutnya proses diteruskan dengan perancangan konsep yang merupakan focus pada perancangan ini.

\section{HASIL DAN PEMBAHASAN}

Hasil pengamatan menunjukan bahwa tungku peleburan yang mungkin dibuat untuk skala rumah tangga adalah tungku peleburan logam non ferro Karena logam non ferro lebih mudah untuk di daur ulang. Logam non ferro dapat langsung dilebur (remelting) lalu dicetak tanpa memerlukan proses ekstraksi lainnya. Proses peleburan logam ini akan terjadi jika temperature lingkungan mencapai temperature lebur logam tersebut. Temperatur kelompok logam non ferro lebih rendah dibandingkan dengan logam ferro. Temperatur lingkungan akan naik jika dilakukan proses pemanasan. Proses pemanasan membutuhkan energi. Daftar spesifikasi tungku yang dirancang dapat dilihat pada Tabel 1.

Fungsi dari cowper adalah untuk menyerap panas yang masih dibawa oleh udara hasil peleburan dan melepaskan panas ke udara untuk kemudian dialirkan ke dalam dapur peleburan untuk membantu meningkatkan temperatur dapur peleburan tersebut. Berdasarkan fungsi ini maka yang harus diperhatikan dalam proses perancangan adalah temperatur udara hasil peleburan, susunan sekat batu tahan api untuk menyerap dan melepas panas, dan kemudahan laju aliran. 
Tabel 1. Daftar spesifikasi.

\begin{tabular}{llc}
\hline Aspek & Daftar Spesifikasi & D/W \\
\hline Geometri & Diameter casing maksimum $600 \mathrm{~mm}$ & $\mathrm{D}$ \\
& Tinngi casing maksimum $1000 \mathrm{~mm}$ & $\mathrm{D}$ \\
Kinematika & Alat dapat dipindah-pindahkan & $\mathrm{D}$ \\
Gaya & Pemasukan dan pengeluaran udara stabil & $\mathrm{D}$ \\
Energi & Masukan energi termal dapat mencapai temperature $700^{\circ} \mathrm{C}$ & $\mathrm{D}$ \\
& Temperatur udara meninggalkan alat serupa dengan temperatur & $\mathrm{W}$ \\
& ruang. & \\
& Temperatur udara keluar dari alat dan masuk dalam dapur & $\mathrm{W}$ \\
& minimal 300 C. & $\mathrm{D}$ \\
Material & Refaktori mampu menahan sampai temperature $1000^{\circ} \mathrm{C}$ & $\mathrm{D}$ \\
& Casing terbuat dari plat logam & $\mathrm{D}$ \\
Sinyal & Pengukuran temperature menggunakan thermocouple & $\mathrm{D}$ \\
& Pengukuran laju aliran menggunakan flowmeter & $\mathrm{D}$ \\
Perawatan & Perawatan sederhana & $\mathrm{D}$ \\
Perakitan & Mudah dirakit & $\mathrm{D}$ \\
Keselamatan & Aman bagi operator & $\mathrm{W}$ \\
\hline
\end{tabular}

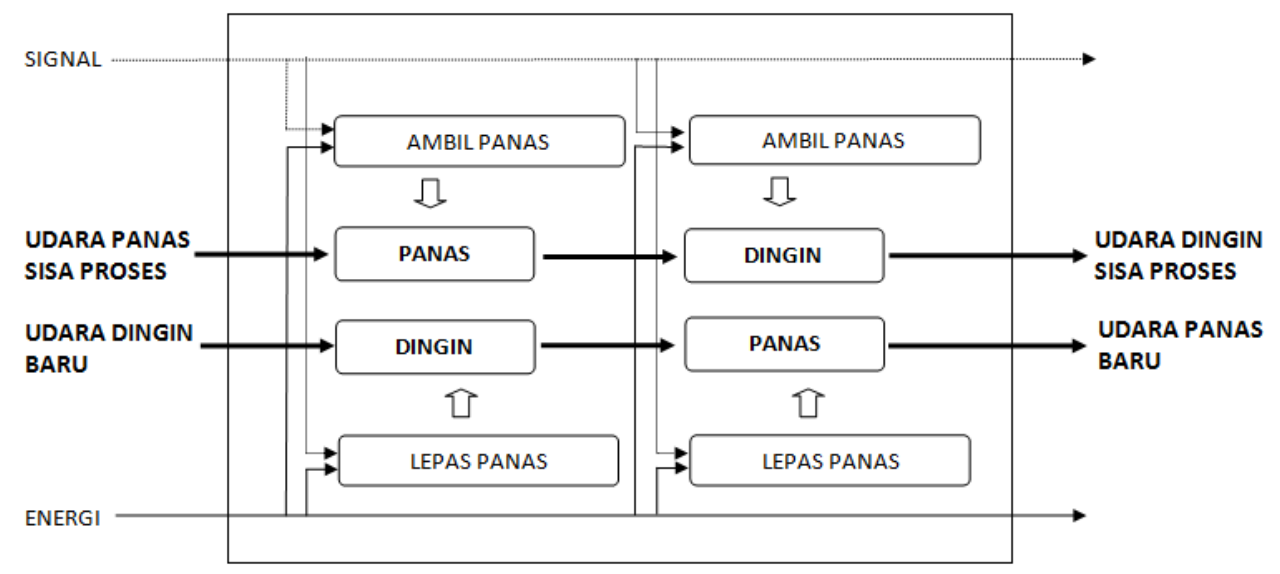

Gambar 2. Blok diagram struktur fungsi



Gambar 3. Prinsip solusi umum.

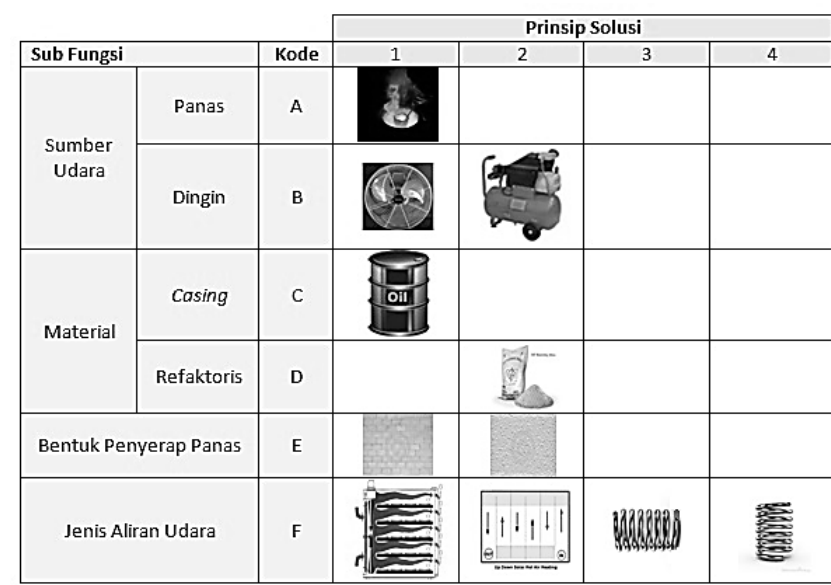

Gambar 4. Prinsip solusi spesifik.

Struktur fungsi dari perancangan ini adalah temperatur udara panas yang dihasilkan oleh proses peleburan harus dialiran dan masuk kedalam cowper untuk kemudian bergerak memanasi 
dinding sekat batu tahan api. Hal ini akan berlangsung terus sampai temperatur sekat batu tahan api panas. Setelah itu akan dialirkan udara untuk mendinginkan sekat batu tahan api tersebut dan disalurkan kedalam dapur. Blok diagram struktur fungsi ini dapat dilihat pada Gambar 2.

Tabel 2. Konsep varian.

\begin{tabular}{llllllllllllll}
\hline Kode & \multicolumn{1}{l}{ Konsep Varian } & \multicolumn{1}{c}{ Kode } & \multicolumn{2}{l}{ Konsep Varian } \\
\hline KV-1 & A1 & B1 & C1 & D2 & E1 & F1 & KV-9 & A1 & B1 & C1 & D2 & E2 & F1 \\
KV-2 & A1 & B1 & C1 & D2 & E1 & F2 & KV-10 & A1 & B1 & C1 & D2 & E2 & F2 \\
KV-3 & A1 & B1 & C1 & D2 & E1 & F3 & KV-11 & A1 & B1 & C1 & D2 & E2 & F3 \\
KV-4 & A1 & B1 & C1 & D2 & E1 & F4 & KV-12 & A1 & B1 & C1 & D2 & E2 & F4 \\
KV-5 & A1 & B2 & C1 & D2 & E1 & F1 & KV-13 & A1 & B2 & C1 & D2 & E2 & F1 \\
KV-6 & A1 & B2 & C1 & D2 & E1 & F2 & KV-14 & A1 & B2 & C1 & D2 & E2 & F2 \\
KV-7 & A1 & B2 & C1 & D2 & E1 & F3 & KV-15 & A1 & B2 & C1 & D2 & E2 & F3 \\
KV-8 & A1 & B2 & C1 & D2 & E1 & F4 & KV-16 & A1 & B2 & C1 & D2 & E2 & F4 \\
\hline
\end{tabular}

Tabel 3.Pemilihan kombinasi varian



Berdasarkan struktur fungsi yang adalah disusunlah prinsip solusi untuk masing-masing sub fungsi yang meliputi sumber udara panas, sumber udara, material isolator, laju aliran dan konsep perpindahan panas dan jenis aliran udara. Sumber udara panas adalah gas buang hasil peleburan dapur, sedangkan sumber udara dingin berasal dari blower dan kompresor. Material isolator yang digunakan adalah batu tahan api dengan tiga pilihan bentuk, yaitu batu bata, pasir dan kowi. Sedangkan casing terbuat dari baja dengan pilihan memanfaatkan tong bekas oli, menggunakan plat atau melakukan proses pengecoran. Proses perpindahan panas akan terjadi pada dinding dan sekat yang dibuat dalam cowper. Bentuk dinding dan sekat tersebut juga mempunyai tiga pilihan, yaitu 
berulir, rata, atau kotak-kotak. Sedangkan pilihan untuk arah aliran udara adalah lurus vertikal, luruh horisontal, berulir vertikal dan berulir horisontal.

Prinsip solusi ini dapat dilihat pada Gambar 3. Prinsip solusi yang ada dianalisa berdasarkan hasil pengamatan dan kondisi penggunaannya. Hasil analisa memberikan prinsip solusi yang lebih spesifik seperti terlihat pada Gambar 4 dan memberikan 16 konsep varian seperti tercantum pada Tabel 2. Konsep varian ini dibuat dengan memperhatikan kesesuaian antar sub fungsi.

Tabel 4.Kriteria evaluasi

\begin{tabular}{clccccccc}
\hline & \multicolumn{2}{c}{ Kriteria Evaluasi } & \multicolumn{2}{c}{ KV-6 } & \multicolumn{2}{c}{ KV-13 } & \multicolumn{2}{c}{ KV-14 } \\
No. & Kriteria & wt. & N & B & N & B & N & B \\
\hline 1. & Perpindahan Panas & 0,25 & 9 & 2,25 & 8 & 2,00 & 9 & 2,25 \\
2. & Kemudahan Pembuatan & 0,20 & 8 & 1,60 & 8 & 1,60 & 8 & 1,60 \\
3. & Operasi & 0,20 & 8 & 1,60 & 8 & 1,60 & 8 & 1,60 \\
4. & Perawatan & 0,17 & 8 & 1,36 & 8 & 1,36 & 9 & 1,53 \\
5. & Kemudahan Perbaikan & 0,18 & 8 & 1,44 & 8 & 1,44 & 9 & 1,62 \\
\hline \multicolumn{2}{r}{ Jumlah } & 1,00 & & 8,25 & & 8,00 & & 8,60 \\
\hline
\end{tabular}

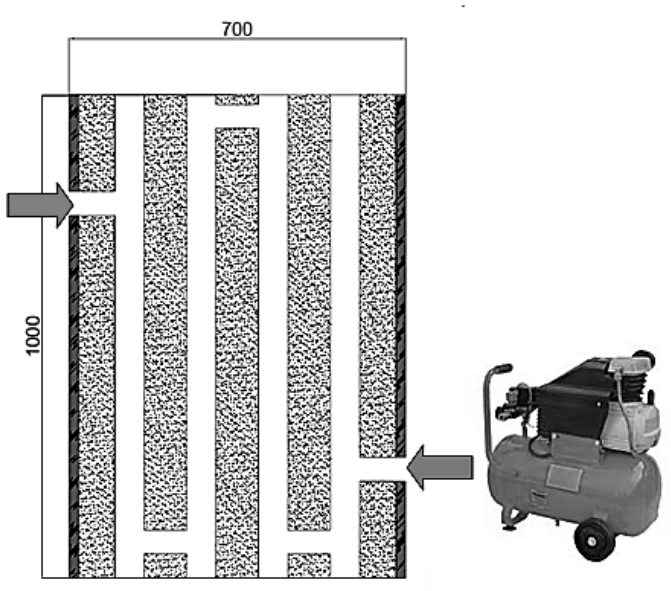

a. Sketsa varian terpilih.



b. Sketsa sistem dengan varian terpilih.

Gambar 5. Sketsa varian terpilih

Evaluasi kualitatif terhadap 16 konsep varian menghasilkan 3 varian yang memenuhi spesifikasi, yaitu KV-6, KV-13 dan KV-14 seperti terlihat pada Tabel 3. Analisa kuantitatif yang dilakukan terhadap aspek perpindahan panas, kemudahan untuk dibuat, kemudahan untuk dioperasikan, kemudahan untuk dirawat dan kemudahan untuk diperbaiki konstruksinya maka diperoleh nilai bobot seperti terlihat pada Tabel 4. Bobot tertinggi diperoleh KV-14, yaitu 8,60. Berdasarkan bobot ini maka KV-14 dipilih untuk perancangan tahap selanjutnya.Varian terpilih adalah sebuah cowper yang dibuat dengan menggunakan drum bekasoli sebagai badan (casing) luar menggunakan sistem aliran udara horisontal dengan sekat batu tahan api berbentuk serbuk (ramming) yang dibuat langsung mengikuti desain sekat batu tahan api dan menggunakan kompresor sebagai sumber udara (Gambar 5). Penggunaan drum olibekas sebagai casing luar akan membantu proses daur ulang dan mempermudah konstruksi pembuatan. Penggunaan batu tahan api berbentuk serbuk untuk membentuk dinding bagian selain akan mempermudah proses pembuatan cowper juga akan memiliki perpindahan panas yang lebih homogen pada setiap luasan permukaan karena tidak adanya batas seperti pada penggunaan batu tahan api berbentuk bata. Flowmeter dan thermocouple akan digunakan untuk memastikan kestabilan aliran dan temperatur. Mengingat proses fungsinya maka cowper akan dibuat berpasangan atau 2 buah untuk 1 sistem 


\section{KESIMPULAN}

Telah dibuat suatu konsep rancangan sepasang Cowper dengan metode VDI 2221 untuk meningkatkan temperatu tungku peleburan.Cowper ini menggunakan casing drum oli bekas, batu tahan api berbentuk serbuk dengan model bukan batu bata, arah aliran udara vertikal dan kompresor sebagai sumber udara. Cowper juga akan menggunakan flowmeter dan thermocouple untuk menjaga laju aliran dan temperatur.

\section{UCAPAN TERIMA KASIH}

Perancangan ini adalah bagian dari penelitian yang dibiayai oleh Universitas Trisakti.

\section{DAFTAR PUSTAKA}

[1] Carvalho, M. d G. dan M. Nogueira, Improvement of Energy Efficiency in Glass-Melting Furnaces, Cement Kilns and Baking Ovens, Applied Thermal Engineering, 1997, Vol. 17, No. 8-10, hal. 921-933.

[2] Dai, F-q, Huang, S-y, Li, S-h and K., Liu, Study of a ceramic burner for shaftless stoves, International Journal of Minerals, Metallurgy and Materials, 2009, Volume 16, hal. 149.

[3] Ridgion, J.M., Willmott, A.J.andJ.H.Thewlis, Ananalogue computer simulation of a Cowper Stove, Computer Journal, 1964, Vol. 7 No. 3, hal. 188-196.

[4] Sukarnoto, T., Soeharsono, dan Supriyadi, Perancangan Sistem Buka Tutup Pintu Geser Kompak pada Busway, Proceeding Seminar Nasional Tahunan Teknik Mesin XI dan Thermofluid IV, UGM, Yogyakarta, 16-17 Oktober 2012.

[5] Tscheliesnig, P., dan G. Schauritsch, AT and AE monitoring for a pressure equipment (cowper) for steel Production, prosiding of 11th European Conference on Non-Destructive Testing (ECNDT 2014), Prague, Czech Republic, 6-10 October2014.

[6] Yusep Mujalis, Yosca Octaviano, Benny Siantury, Tono Sukarnoto dan Rianti Dewi SulametAriobimo, Perancangan Tungku Peleburan Logam Buatan Sendiri, Prosiding Seminar InovasiTeknologidanRekayasaIndustri 2014, Universitas Andalas, Padang, 26 Agustus 2014.

[7] Woodcroft, B., Chronological Index of Patents Applied for and Patents Granted, for the Year 1857, 1857, Paten No. 1404.

[8] Ziebik, A. dan Stanek, W., Identification of the influence of blast-furnace working parameters uponthe supply and net calorific value of blast furnace gas, Acta Montanistica Slovaca, 2003, Vol. 8 No. 4, hal. 194-196. 